\title{
An Efficiency Evaluation of Iron Concentrates Flotation Using Rhamnolipid Biosurfactant as a Frothing Reagent
}

\author{
Hamid Khoshdast ${ }^{\dagger}$, Abbas Sam \\ Department of Mining Engineering, Shahid Bahonar University, Kerman, Iran
}

\begin{abstract}
The effect of a rhamnolipid biosurfactant produced by a Pseudomonas aeruginosa MA01 strain on desulfurization of iron concentrates was studied. Surface tension measurement and frothing characterization indicated better surface activity and frothability of rhamnolipid compared to methyl isobutyl carbinol (MIBC) as an operating frother. Reverse flotation tests using rhamnolipid either as a sole frother or mixed with MIBC, showed that the desulfurization process is more efficient at $\mathrm{pH} 4.5$ and high concentration of rhamnolipid in the presence of MIBC. However, under these conditions water recovery decreased due to the change in rhamnolipid aggregates morphology. Results from the present study seemed promising to introduce the biosurfactant from Pseudomonas aeruginosa as a new frother.
\end{abstract}

Keywords: Desulfurization, Froth flotation, Iron concentrate, Rhamnolipid biosurfactant

\section{Introduction}

Synthetic chemicals from petroleum origins are now coming to a turning point with regards to their hazardous problems to living organisms. Concerns about environmental protection and the safety surrounding health have introduced an interest in developing biomaterials such as naturally occurring surfactants (biosurfactants), biodyes, biopolymers, and fine chemicals [1]. Surfactants (surface active agents) are amphiphilic molecules with both hydrophilic and lipophilic moieties. Biosurfactant is a microbial origin surfactant produced as a co-metabolite by particular microorganisms. Due to its advantages over the synthetic surfactant, i.e. high effectiveness, low toxicity to microorganisms and environmental compatibility, biosurfactants have had more and more environmental applications in recent years [2].

Among the various species of biosurfactants, much work has been done on rhamnose containing microbial surfactants produced by Pseudomonas aeruginosa strains. This ubiquitous environmental bacterium can be isolated from many different habitats including water, soil and plants. These Rhamnolipids produced by P. aeruginosa microorganisms are usually a mixture of two or four species. They differ by the length of hydrophobic chains (from $\mathrm{C}_{8}$ to $\mathrm{C}_{12}$ ), some of which are unsaturated with one double bond. However, under usual growth conditions, two main homologues are primarily obtained: monorhamnolipid (RL-1) and dirhamnolipid (RL-2). Numerous articles consider the process of microbial cultivation of rhamnolipid type biosurfactants on different substrates and their potential application [3-10].
Although there are a number of studies related to the direct application of microorganisms in flotation and flocculation of minerals which are well reviewed by Hanumantha Rao et al. [11] and Khoshdast and Sam [12], few scientific researches which apply biosurfactants have been found. The only available work on using rhamnolipid biosurfactants in flotation of coal and minerals was done by Fazaelipoor et al. [13]. They studied frothing characteristics and flotation applicability of rhamnolipid type biosurfactants as a frother. These biosurfactants showed better surface-activity and static frothability, i.e. frother height and half-life, in comparison with methyl isobutyl carbinol (MIBC). However, some points challenging the results reported by Fazaelipoor et al. [13] are: 1) diesel oil being used as a biosurfactant solvent. After solvent evaporation, heavy hydrocarbon residuals of diesel oil would remain which increase the impurity of crude biosurfactant. This low purity of their product $(<50 \%)$ disputes the validity of surface tension and frothing characterization results; 2) only two point values were reported in their work for reporting frothability results; whereas, least reliable point value is four; and 3) all types of coal are of relative natural hydrophobicity. Thus, flotation applicability of biosurfactant in this study would not be highly reliable. However, products of $72-79 \%$ recovery with $10-15.5 \%$ ash content supporting $55-57.5 \%$ efficiency seem to be promising to introduce rhamnolipid type biosurfactants as a new "biofrother".

In this research we report the production of a biosurfactant in concentrated form from a bacterial species named P. aeruginosa, the biosurfactant physical/chemical and frothing characteriza- (c) This is an Open Access article distributed under the terms of the Creative Commons Attribution Non-Commercial License (http://creativecommons. org/licenses/by-nc/3.0/) which permits unrestricted non-commercial use, distribution, and reproduction in any medium, provided the original work is properly cited.
Received September 06, 2011 Accepted February 15, 2012

${ }^{\dagger}$ Corresponding Author

E-mail: khoshdast_hamid@yahoo.com

Tel: +98-913-532-5904 Fax: +98-341-212-1003 
tion, and its application to iron concentrate desulfurization using flotation as a frother and/or co-frother.

\section{Materials and Methods}

\subsection{Microorganism, Media and Growth}

A pure strain of P. aeruginosa MA01 (accession no. GQ478669) was obtained from the Molecular Genetics Laboratory at National Institute of Genetic Engineering and Biotechnology (NIGEB) in Tehran, Iran. The soybean oil-mineral salts medium was used consisting of: soybean oil ( $40 \mathrm{~g} / \mathrm{L}), \mathrm{NaNO}_{3}(3 \mathrm{~g} / \mathrm{L}), \mathrm{MgSO}_{4} \cdot 7 \mathrm{H}_{2} \mathrm{O}$ $(0.25 \mathrm{~g} / \mathrm{L}), \mathrm{KH}_{2} \mathrm{PO}_{4}(0.25 \mathrm{~g} / \mathrm{L})$, yeast extract $(1 \mathrm{~g} / \mathrm{L})$, and distilled $\mathrm{H}_{2} \mathrm{O}$ to $1,000 \mathrm{~mL}$. Seed culture was prepared by transferring a loopful from a fresh culture grown onto nutrient agar slant into $25 \mathrm{~mL}$ of mineral salts medium contained in 250 -mL Erlenmeyer flask. The flask was incubated at $200 \mathrm{rpm}$ and $30^{\circ} \mathrm{C}$ for $24 \mathrm{hr}$.

\subsection{Biosurfactant Production}

Rhamnolipid production was carried out in 2-L Erlenmeyer flasks containing $700-\mathrm{mL}$ aliquots of the fermentation medium under test. The flasks were inoculated with the seed culture at $2 \%$ $\mathrm{v} / \mathrm{v}$ and incubated under shaking conditions $(200 \mathrm{rpm})$ at $30^{\circ} \mathrm{C}$ for 10 days. The cell suspension was centrifuged (Sigma model 6-16K; SIGMA Laborzentrifugen GmbH, Osterode am Harz, Germany) $16,000 \times \mathrm{g}$ for $15 \mathrm{~min}$ at $4^{\circ} \mathrm{C}$ to prepare the cell-free supernatant (CFS). The CFS was acidified with $1 \mathrm{~N} \mathrm{HCl}$ to $\mathrm{pH} 2$ and left overnight at $4^{\circ} \mathrm{C}$ to precipitate rhamnolipids. The precipitate was harvested by centrifugation at $18,000 \times \mathrm{g}$ for $50 \mathrm{~min}$ at $4^{\circ} \mathrm{C}$. Afterwards, the precipitate was washed by acidified $(\mathrm{pH}$ 2) distilled water and centrifuged at $18,000 \times \mathrm{g}$ for $10 \mathrm{~min}$ at $4^{\circ} \mathrm{C}$. Rhamnolipid was mixed with an equal volume of ethyl acetate, vigorously shaken for $10 \mathrm{~min}$, and centrifuged at $18,000 \times \mathrm{g}$ for 15 $\min$ at $4^{\circ} \mathrm{C}$. Finally, the pooled organic phase was transferred to a new vessel and evaporated under vacuum (Buchi model R-200; Buchi Labortechnik AG, Essen, Germany) at $40^{\circ} \mathrm{C}$. After solvent evaporation, about $9 \mathrm{~g}$ of a viscous honey-colored biosurfactant product was extracted per liter from the culture medium.

\subsection{Characterization of Biosurfactant}

The crude biosurfactant had some impurities. Therefore the purification of crude biosurfactant was carried out using column chromatography according to the method of Sanchez et al. [6] with minor modifications. Briefly, a slurry of $20 \mathrm{~g}$ silica gel 60 in chloroform was poured into a glass column chromatography $(2 \times 40 \mathrm{~cm}) .2 \mathrm{~g}$ of crude biosurfactant was dissolved in $4 \mathrm{~mL}$ of chloroform and loaded onto the column. The purification was carried out by washing the column at a flow rate of ca. $1 \mathrm{~mL} /$ min with chloroform (to elute neutral lipids), followed by chloroform: methanol 50:5 (to elute monorhamnolipid fraction) and finally chloroform: methanol 50:50 (to elute dirhamnolipid fraction). Then purified fractions were mixed and the solvents were removed under vacuum and finally, freeze-dried. Each fraction was analyzed using Fourier-transform infrared (FTIR) spectroscopy (Nicolet 6700 FTIR; Thermo Scientific Inc, Waltham, MA, USA) and electrospray mass spectrometry (ES-MS) in an Agilent model LC-MSD-Trap-VL (Classic series; Agilent Technologies, Santa Clara, CA, USA) equipment. For FTIR analysis, a purified biosurfactant sample was placed in between two $\mathrm{CaF}_{2}$ windows, without spacers, and the set was mounted in a thermostated cell holder. The sample holder was thermostated at $25^{\circ} \mathrm{C}$ using a Peltier device (Proteus system from Nicolet). Each spectrum was obtained by collecting 256 interferograms with a nominal resolution of $2 \mathrm{~cm}^{-1}$. The equipment was continuously purged with dry air in order to minimize the contribution peaks of atmospheric water vapor. The chemical structure of the purified fractions was analyzed by scanning from $\mathrm{m} / \mathrm{z} 950$ to 150 using ES-MS. The acquisition parameters were: ion polarity negative, electrospray ionization (ESI) ion source type, dry gas flow-rate $6 \mathrm{~L} / \mathrm{min}$, nebulizer pressure $30 \mathrm{psi}$, temperature $325^{\circ} \mathrm{C}$, and the capillary exit was held at $-127.3 \mathrm{~V}$. The trap drive values were close to 50 , indicating intermediate stability for our compounds.

\subsection{Surface Tension Measurement}

The surface tension was measured by using the ring method. The measurement was conducted under ambient conditions with a Lauda tensiometer (model TD1-C; Lauda, Lauda-Königshofen, Germany) equipped with a platinum ring. The volume of the samples was $10 \mathrm{~mL}$. Each measurement was replicated three times and an average value was reported.

\subsection{Frothing Characterization}

The experiment for froth characterization was performed in a glass cylinder with a height of $100 \mathrm{~cm}$ and an inner diameter of $5 \mathrm{~cm}$. An 85 mesh ceramic air sparger was at the bottom of the column. To determine equilibrium frothability, the variation in equilibrium froth height was measured as a function of air flow rate. Results from equilibrium frothability were applied to calculate the dynamic frothability index (DFI). Froth characteristics of the biosurfactant were compared with those of MIBC as a conventional frother.

\subsection{Reagents and Reverse Flotation Tests}

A bulk iron concentrate sample $\left(\mathrm{d}_{80}=75 \mu \mathrm{m}\right)$ was obtained from Gol-e Gohar Iron Ore Complex, Sirjan, Iran. Two series of tests were conducted at $\mathrm{pH}$ values of $7 \pm 0.2$ and $4.5 \pm 0.2$, respectively. In our previous work, the optimum $\mathrm{pH}$ value for pyrite flotation was found to be 4.5 due to the improved activating performance regarding the collector (Unpublished). The $\mathrm{pH}$ value of 7 had also been selected since it was the best solution condition rhamnolipids shows its maximum surface activity The $\mathrm{pH}$ values were adjusted using sulfuric acid. Potassium amyl xanthate $(\mathrm{PAX})$ was used as a conventional collector $(120 \mathrm{~g} / \mathrm{t})$. MIBC, rhamnolipid biosurfactant, and mixtures of them were used as the frother. Batch tests were carried out using a D-12 Denver flotation machine (Legend Inc., Sparks, NV, USA) equipped with a 1-L cell. With the amount of ore used, the pulp density of the flotation feed became about $20 \%$ solids by weight. Flotation gas rate was based on the natural suction of air into pulp through the shaft of an impeller set at 1,000 rpm. Each sample was conditioned for $5 \mathrm{~min}$. Then PAX collector was added and conditioned for $3 \mathrm{~min}$. After conditioning, the requisite amount of frother was added and conditioned for another $2 \mathrm{~min}$. Flotation was continued for $3 \mathrm{~min}$. Collected samples were filtered, dried, weighed, and analyzed for sulfur and iron content. 


\subsection{Elemental Analysis}

Samples were analyzed at the Central Laboratory of Gol-e Gohar Iron Ore Complex, for their iron and sulfur content measurements. In order to determine Fe contents, $1 \mathrm{~g}$ of each sample was transferred into a 1,000 mL Erlenmeyer flask containing 15 $\mathrm{mL}$ of concentrated $\mathrm{HCl}$. The solution was then heated to just below boiling on the hot plate until the ore dissolved. After the solution cooled, distilled water was added to bring the volume to $1,000 \mathrm{~mL}$. The $500 \mathrm{~mL}$ of solution was then transferred into a 500 $\mathrm{mL}$ Erlenmeyer flask and 5 drops of sulfuric acid was added. Afterwards, $50 \mathrm{~mL}$ of acidified solution was again transferred into a $100 \mathrm{~mL}$ flask and $10 \mathrm{~mL}$ of $10 \%$ ascorbic acid was added. After waiting only about $10 \mathrm{sec}, 10 \mathrm{~mL}$ of buffer solution of $\mathrm{pH} 3.7 \pm$ 0.1 and $10 \mathrm{~mL}$ of $0.5 \%$ ortho-phenanthroline was also added to the solution. Final solution was left for $30 \mathrm{~min}$ and Fe content was photometrically measured at a wave length of $546 \mathrm{~nm}$. Sulfur content was measured using a Stroehlein Analyzer (model CS-mat 6250; Labexchange, Burladingen, Germany) on the base of the instrument's instruction manual. Tungsten powder and iron chips were used as co-smelter and accelerator, respectively. Analysis showed that the bulk iron concentrate contained $0.332 \%$ sulfur and $70.68 \%$ iron.

\subsection{Water Recovery Measurement}

At a constant aeration rate and froth height, the recovery of water depends on the stability of the froth phase [14]. The stability of the froth phase is determined by the stability of liquid lamellae between gas bubbles, which in turn affects the froth water content $[15,16]$. Therefore, the water recovery of the concentrate can be used as a parameter to evaluate the stability of a froth zone [17]. In this regard, the water content of collected froths was weighed and used for water recovery calculations as a measure for three-phase froth stability investigations.

\section{Results and Discussion}

\subsection{Characterization of Biosurfactant}

FTIR and ES-MS were used to determine the chemical structure of purified biosurfactant (data not shown here). FTIR analysis showed the glycolipid nature of the produced biosurfactant by $P$. aeruginosa MA01. Analysis of crude biosurfactant using analytical TLC with an anthrone reagent showed two major components and confirmed the presence of sugar moiety in the composition of biosurfactant. Results from ES-MS indicated the presence of three major monorhamnolipid species: $\mathrm{R}_{1} \mathrm{C}_{10} \mathrm{C}_{10}$, $\mathrm{R}_{1} \mathrm{C}_{10} \mathrm{C}_{12: 1}$, and $\mathrm{R}_{1} \mathrm{C}_{10} \mathrm{C}_{12}$; as well as another three major dirhamnolipid species: $\mathrm{R}_{2} \mathrm{C}_{10} \mathrm{C}_{10}, \mathrm{R}_{2} \mathrm{C}_{10} \mathrm{C}_{12: 1}$, and $\mathrm{R}_{2} \mathrm{C}_{10} \mathrm{C}_{12}$. Among these compounds, $\mathrm{R}_{1} \mathrm{C}_{10} \mathrm{C}_{10}$ and $\mathrm{R}_{2} \mathrm{C}_{10} \mathrm{C}_{10}$ with a 0.5:0.5 molar ratio were the major components of produced rhamnolipid by MA01 strain. The rhamnolipid product was of $98 \%$ purity. Fig. 1 shows the drawn wire frame model of these components drawn by ChemSite Pro demo software (ChemSW Inc., Fairfield, CA, USA) [18].

From Fig. 1, molecular weight (Mw) of the rhamnolipid product can be determined by adding the atomic weights of all the atoms in the formula together [19], and finally:

$$
\begin{aligned}
M w_{\text {Crude Rhamnolipid }} & =0.5 M w_{\text {RL-1 }}+0.5 M w_{\text {RL-2 }} \\
& =0.5 \times 504+0.5 \times 650=577
\end{aligned}
$$
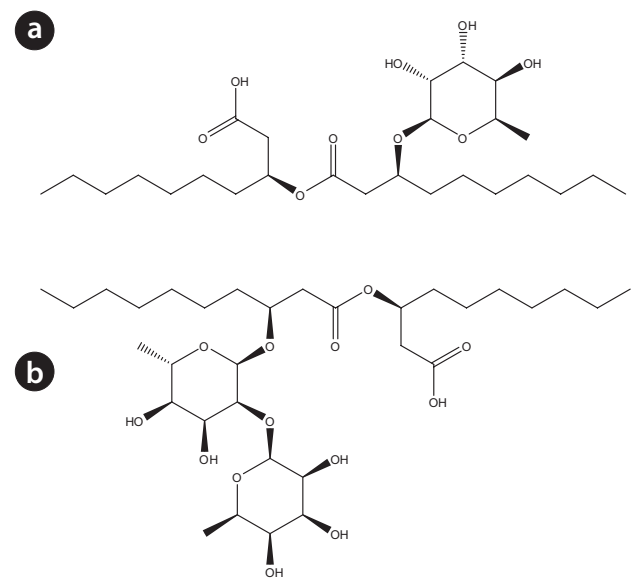

Fig. 1. Identified structure of mono-rhamnolipid $\left(\mathrm{R}_{1} \mathrm{C}_{10} \mathrm{C}_{10}\right.$, a), and di-rhamnolipid $\left(\mathrm{R}_{2} \mathrm{C}_{10} \mathrm{C}_{10}\right.$, b) produced by Pseudomonas aeruginosa MA01 strain.

Amphiphilicity is a fundamental characteristic of any frother. To quantitatively assess it, the so-called hydrophile-lipophile balance (HLB) is widely used, which indicates the relative strength of the hydrophilic and hydrophobic portions of the molecule and can be used to characterize the relative affinity of frother in the water and gaseous phase [20]. Among all experimental and computational methods, Davies' method has been most widely used to determine a surfactant's HLB number, as follows [21]:

$$
\begin{gathered}
H L B=7+\sum(\text { hydrophilic group numbers })+ \\
\sum(\text { lipophilic group numbers })
\end{gathered}
$$

From Fig. 1, one can obtain:

$$
\begin{aligned}
H L B_{\mathrm{RL}-1} & =7+2.1_{(-\mathrm{COOH})}+2.4_{(-\mathrm{COO}-)}+2 \times(1.3)_{(-\mathrm{O}-)} \\
& +3 \times(-0.475)_{\left(-\mathrm{CH}_{3}\right)}+14 \times(-0.475)_{\left(-\mathrm{CH}_{2}\right)} \\
& +7 \times(-0.475)_{(-\mathrm{CH})}+3 \times(1.9)_{(-\mathrm{OH})}=8.3 \\
H L B_{\mathrm{RL}-2} & =7+2.1_{(-\mathrm{COOH})}+2.4_{(-\mathrm{COO}-)}+4 \times(1.3)_{(-\mathrm{O}-)} \\
& +4 \times(-0.475)_{(-\mathrm{CH})}+14 \times(-0.475)_{\left(-\mathrm{CH}_{2}\right)} \\
& +12 \times(-0.475)_{(-\mathrm{CH})}+5 \times(1.9)_{(-\mathrm{OH})}=11.95
\end{aligned}
$$

Thus,

$$
H L B_{\text {Crude Rhamnolipid }}=0.5 \times H L B_{\mathrm{RL}-1}+0.5 \times H L B_{\mathrm{RL}-2}=10.17
$$

\subsection{Surface Tension Measurements}

Different concentrations of biosurfactant in distilled water were prepared, and the surface tension for each sample was measured. The same was done for MIBC. Fig. 2 shows the results. The results indicate the improved ability of the biosurfactant to reduce surface tension of water compared to that of MIBC. There might be two reasons responsible for these results. First, rhamnolipid biosurfactant has a much higher molecular weight compared to MIBC $(102.17 \mathrm{~g} / \mathrm{mol})$. This higher Mw leads to a more viscous, and hence more stable liquid lamellae. Second, there is only one -OH group in MIBC and this group will interact with water molecules to form an oriented monolayer at the surface. However, in biosurfactant, there are several oxygenated units in 


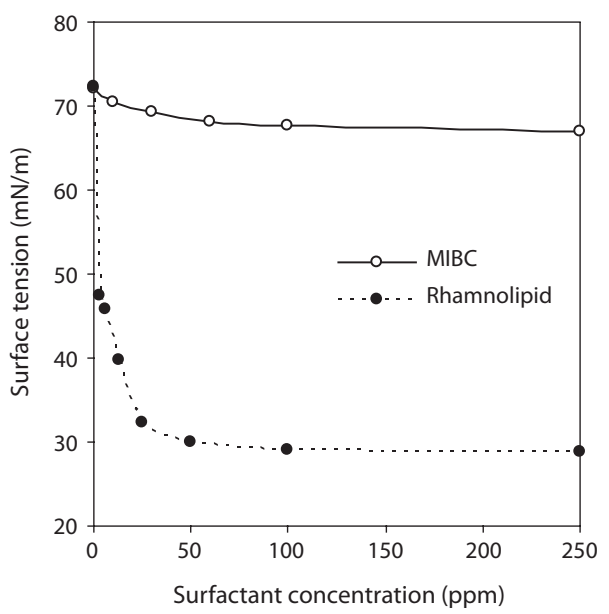

Fig. 2. Comparison between the biosurfactant and methyl isobutyl carbinol (MIBC) in reducing surface tension of distilled water.

the molecular chain (Fig. 1) and each unit can interact with water molecules through hydrogen bonding, causing the molecules to tend to lie flat at the surface, possibly increasing the viscosity of the liquid film.

\subsection{Frothing Characterization}

Frothers, which are usually non-ionic heteropolar molecules, were added to create a reasonably stable froth. The polar end of a frother molecule forms hydrogen bonds with water. The non-polar end concentrates at the air/water interface. This phenomenon alters the surface tension of water. Changing the surface tension of water is a measure of the surface activity of surfactants. In general, an increase in surface activity results in increased frothability and froth stability [22]. Surface tension measurements showed that at equal concentrations, the biosurfactant had higher surface activity. So, the biosurfactant may be expected to show better frothability compared to MIBC. Since the ability to reduce the surface tension of water is not the only parameter for the evaluation of the frothability of a surfactant, the height of froth produced by the rhamnolipid product was compared to that of MIBC. For this purpose, the equilibrium height of froth was measured as a function of aeration rate at different surfactant concentrations. Fig. 3 shows the results. A statistically paired t-test showed a significant difference between froth heights produced by the surfactants [23]. Rhamnolipid produced higher froth heights compared to MIBC.

Due to the fact that there are some limitations in only using froth height to explain the frothing capacity of frothers, DFI is aimed to characterize flotation frothers [24]. The DFI is actually derived from equilibrium data and is a proprietary characteristic of any frother. In order to determine the DFI of a frother, the volume of produced froth is plotted against gas flow rate to calculate the retention time of froth:

$$
r t=\frac{\Delta V}{\Delta Q}
$$

where $r t$ is the froth retention time (s), $V$ the gas volume (in liquid and foam, $\left.\mathrm{cm}^{3}\right)$ and $Q$ the gas flow rate $\left(\mathrm{cm}^{3} / \mathrm{sec}\right)$. For weaker frothers, the curves are concave and in such cases it is easy to identify the linear part, which is in accordance with Eq. (2). For the more powerful frothers, the volume-gas flow rate plots do
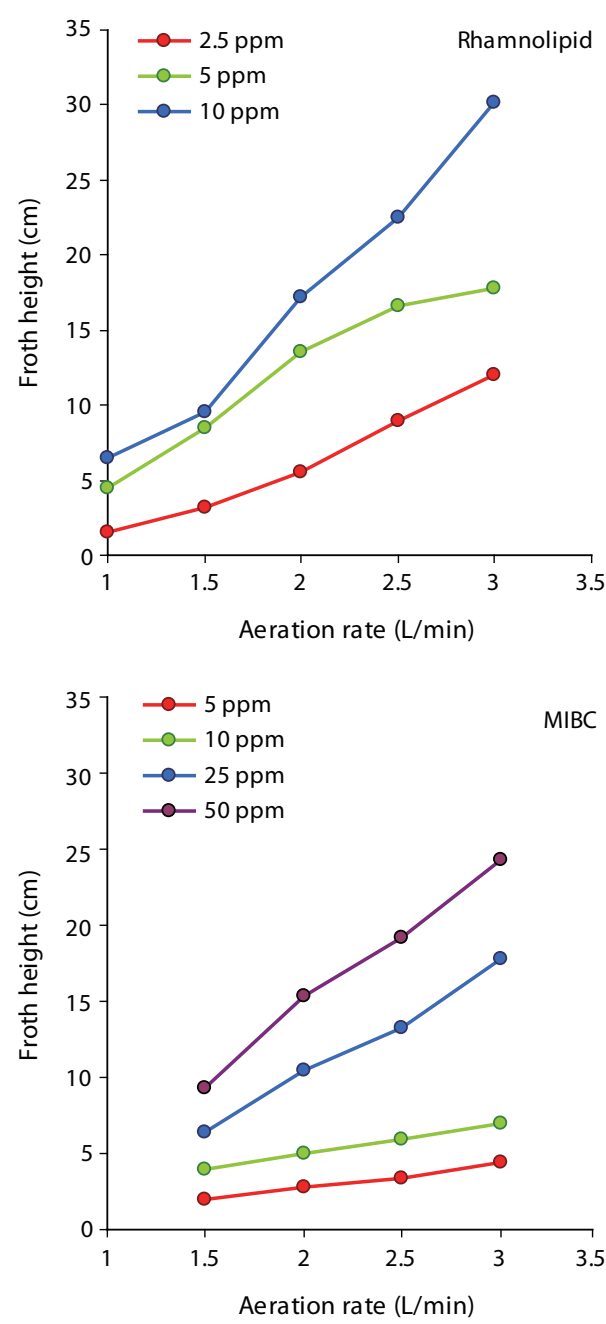

Fig. 3. Froth height as a function of air flow rate at different concentrations of surfactants. MIBC: methyl isobutyl carbinol.

not lend themselves to easy analysis. At concentrations higher than $10 \mathrm{ppm}$, it was observed that in the experiments with rhamnolipid, the recording and reproducibility of froth height measurements was poor. The foam's character was, in this case, visibly different. It appeared to be getting attached to the walls of the container due to very high stability and it was difficult to read exactly the height of the foam. Fortunately, only the $V=f(Q)$ curves for low frother concentrations are important for the determination of DFI, and these curves can easily be linearized for strong frothers [24]. The DFI was calculated using the following relationship $[25,26]$ :

$$
D F I=\left(\frac{\partial r t}{\partial c}\right)_{c=0}
$$

The DFI values for rhamnolipid and MIBC used in this study were obtained 597,091 and 34,670 s.dm $3 / \mathrm{mol}$, respectively. These values show how much the froth produced by rhamnolipids can be stable which may be a disadvantage for a surfactant to be accepted as a flotation frother, because froths with extra high stability cause problems in downstream processes such as thickening, pumping, etc. Fortunately, in the reverse flotation tests of this study, collected froths were observed to have an appropriate 


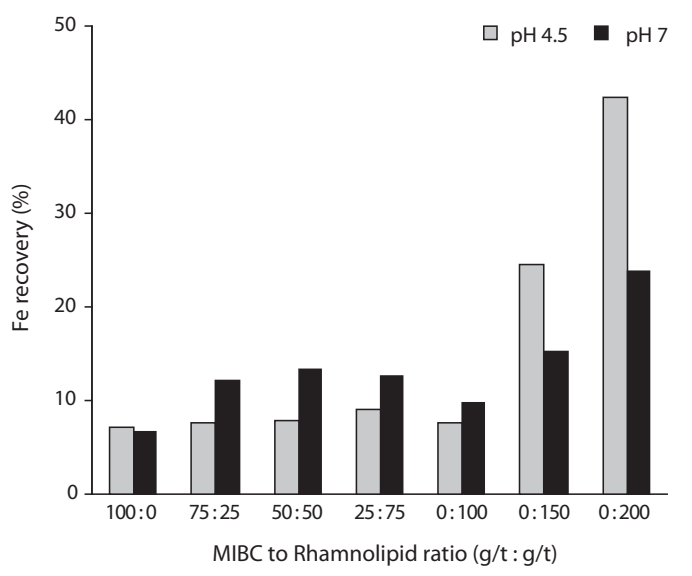

Fig. 4. Iron recovery to the floated products (tailings). MIBC: methyl isobutyl carbinol.

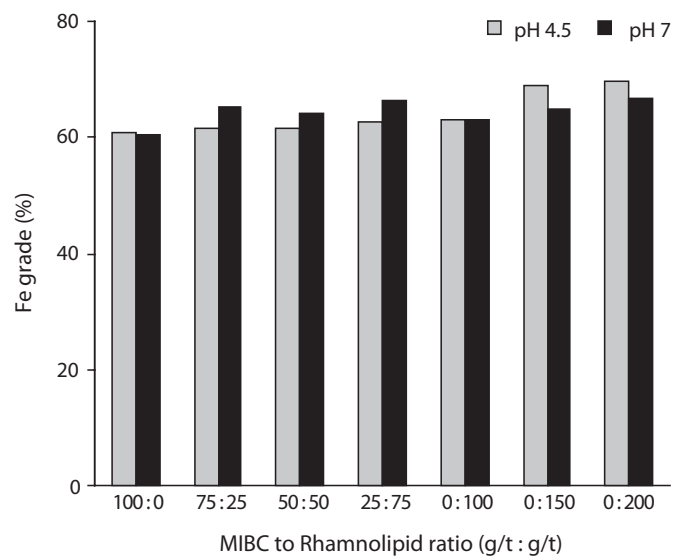

Fig. 5. Fe grade in the floated products (tailings). MIBC: methyl isobutyl carbinol.

stability and collapsed immediately after being discharged from the cell, which $f$ was probably due to their low solid content.

\subsection{Reverse Flotation Tests}

Figs. 4 and 5 show iron recovery and grade for floated products (tailings), respectively. As seen, at both $\mathrm{pH}$ values iron recovery and grade increase by rhamnolipid concentration either in the presence and absence of MIBC. Sulfur content in products that remained in the cell (concentrates) is shown in Fig. 6. As shown, at $\mathrm{pH} 4.5$, sulfur content decreased by increasing rhamnolipid concentration. By comparing Figs. 4 to 6, the increase in iron by increasing rhamnolipid concentration can be ascribed to the improved recovery of pyrite minerals. In contrast, at $\mathrm{pH} 7$, the variations of sulfur content are not considerable. Thus, the improved iron recovery to the floated tailings may be due to carrying valuable iron minerals, i.e. magnetite and hematite, to the froth. It is known that the zero points of charge for hematite and magnetite are obtained at $\mathrm{pH}$ values of 5 and 6.5, respectively [27]. In addition, the optimum $\mathrm{pH}$ value for an efficient flotation result of pyrite is 4.5 . Therefore, the decrease in pyrite content of the floated product by increasing $\mathrm{pH}$ from 4.5 to 7 can be mainly

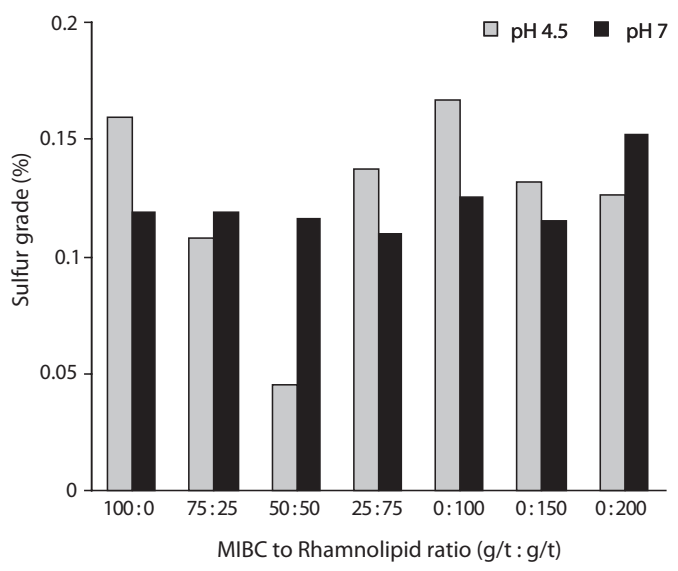

Fig. 6. Sulfur content in the remaining products (concentrates). MIBC: methyl isobutyl carbinol.

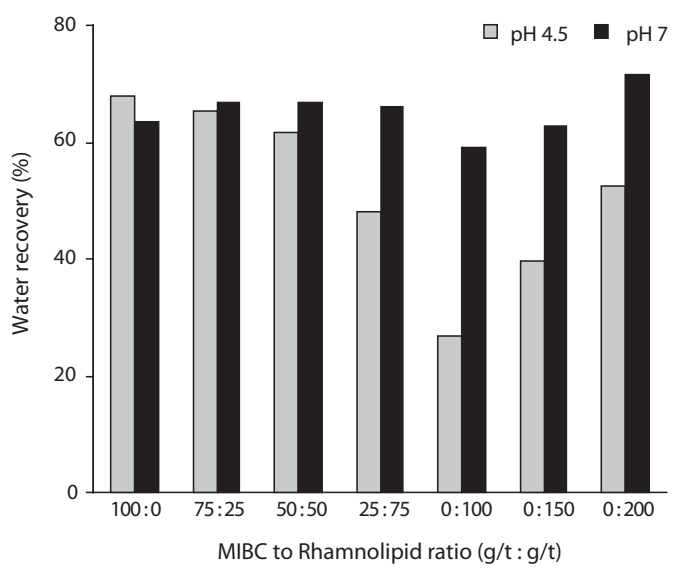

Fig. 7. Water recovery values for flotation tests at different $\mathrm{pH}$ values. MIBC: methyl isobutyl carbinol.

ascribed to loosing efficiency of anionic PAX collector used in this study. The reason for increasing iron recovery at both $\mathrm{pHs}$ by increasing rhamnolipid concentration may be due to the high frothing power of rhamnolipid relative to MIBC. Referring to molecular weight-HLB diagram [26, 28, 29], rhamnolipids with their very high molecular weight and HLB value can be categorized as a "powerful" frother; MIBC with smaller molecular weight and HLB can act more "selectively". Khoshdast et al. [30] compared frothing power and selectivity of rhamnolipid biosurfactants with frothers commercially used in mineral flotation practices. They showed that rhamnolipids act more powerful improving the flotation of coarse and highly dense particles. Whereas, MIBC showed better selectivity and could be applied in the flotation of fines. Therefore, the increase of iron content in the floated products by rhamnolipid concentration can be ascribed to the improvement in the carrying capacity of bubbles for dense particles of iron bearing minerals.

\subsection{Water Recovery Measurements}

Water recovery values for test plans are shown in Fig. 7. At pH 7 , water recovery increased by increasing the rhamnolipid con- 


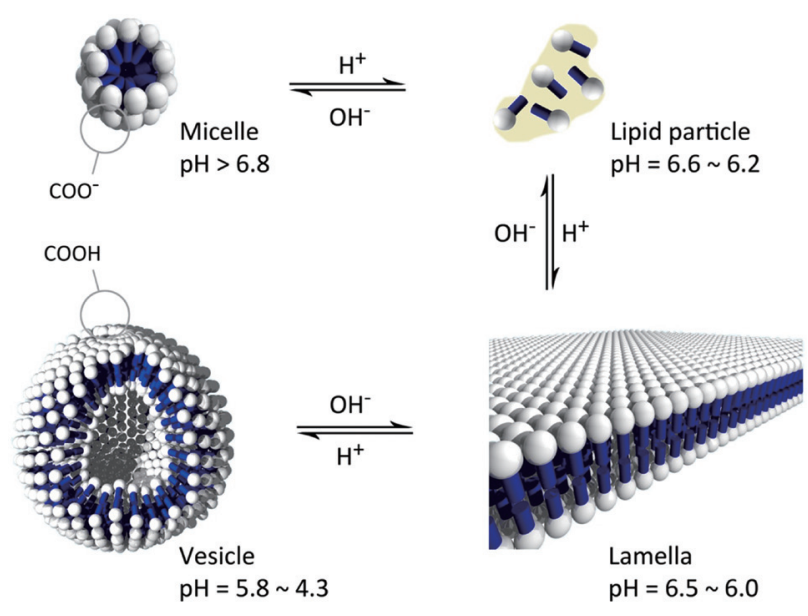

Fig. 8. The $\mathrm{pH}$-sensitive conversion of molecular aggregates of rhamnolipids [31, 32].

centration. In the absence of MIBC, water recovery significantly increased as rhamnolipid concentration increased. At $\mathrm{pH} 4.5$, water recovery decreased by increasing the rhamnolipid concentration. As $\mathrm{pH}$ decreased into an acidic condition the morphologies of rhamnolipid molecules aggregates were reversibly altered from micelles to lipid particles, then lamella and finally to vesicles (Fig. 8) [31]. These changes were attributed to the molecular structure and charge of the rhamnolipid [33]. Considering that the pKa for rhamnolipid is 5.6, the negative charge of the polar head of the rhamnolipid would decrease when the $\mathrm{pH}$ decreased from neutral to acidic values and thus, the interaction between the polar heads of the rhamnolipid with water molecules would also decrease and finally, the surface activity of rhamnolipid would decrease [31, 34, 35]. Therefore, at this condition, water recovery has been influenced by MIBC concentration and decreased by the decrease in MIBC concentration. In the absence of MIBC, although water recovery increased by rhamnolipid concentration it is still lower than MIBC system. These results imply how inefficient rhamnolipids were at acidic $\mathrm{pH}$ values.

\section{Conclusions}

The following conclusions can be drawn from this work: 1) The rhamnolipid product showed better surface activity and frothing capacity compared to MIBC due to its higher molecular weight and multi-oxygenated structure, 2) Desulfurization of an iron concentrate was studied through a set of reverse flotation tests using rhamnolipid either as the sole frother or mixed with MIBC. Results showed that iron recovery on the floated product increased by rhamnolipid concentration. In addition, sulfur content of the remaining concentrate decreased as rhamnolipid concentration increased, 3) Water recovery from rhamnolipid significantly decreased as $\mathrm{pH}$ decreased to an acidic condition. This is due to the morphological changes of rhamnolipid aggregates from micelle to vesicle decreasing surface activity of rhamnolipid biosurfactant.

Although having good frothability and biodegradability makes this biosurfactant a promising frother in flotation practices; more detailed studies are required to confirm if rhamnolipids have the appropriate capability to be accepted as an alternative regarding conventional synthetic frothers. Moreover, another question concerns whether or not rhamnolipids have the proper collecting properties in order to make the interaction with the surfaces of minerals possible.

\section{Acknowledgments}

The authors would like to acknowledge the Gole-e-Gohar Iron and Steel Research Centre, Mineral Processing Department and Laboratory (Sirjan, Iran) for their financial support during this research.

\section{References}

1. Ishigami Y. Characterization and functionalization of biosurfactants. In: Esumi K, Ueno M, eds. Structure-performance relationships in surfactants. 2nd ed. New York: Marcel Dekker Inc.; 2003. p. 285-308.

2. Fu H, Zeng G, Zhong H, et al. Effects of rhamnolipid on degradation of granular organic substrate from kitchen waste by a Pseudomonas aeruginosa strain. Colloids Surf. B Biointerfaces 2007;58:91-97.

3. Helvaci SS, Peker S, Özdemir G. Effect of electrolytes on the surface behavior of rhamnolipids R1 and R2. Colloids Surf. B Biointerfaces 2004;35:225-233.

4. Özdemir G, Peker S, Helvaci SS. Effect of $\mathrm{pH}$ on the surface and interfacial behavior of rhamnolipids R1 and R2. Colloids Surf. A Physicochem. Eng. Asp. 2004;234:135-143.

5. Cohen R, Exerowa D. Surface forces and properties of foam films from rhamnolipid biosurfactants. Adv. Colloid. Interface Sci. 2007;134-135:24-34.

6. Sánchez M, Aranda FJ, Espuny MJ, et al. Aggregation behaviour of a dirhamnolipid biosurfactant secreted by Pseudomonas aeruginosa in aqueous media. J. Colloid Interface Sci. 2007;307:246-253.

7. York JD, Firoozabadi A. Comparing effectiveness of rhamnolipid biosurfactant with a quaternary ammonium salt surfactant for hydrate anti-agglomeration. J. Phys. Chem. B 2008;112:845-851.

8. Pornsunthorntawee O, Chavadej S, Rujiravanit R. Solution properties and vesicle formation of rhamnolipid biosurfactants produced by Pseudomonas aeruginosa SP4. Colloids Surf. B Biointerfaces 2009;72:6-15.

9. Pornsunthorntawee O, Wongpanit P, Chavadej S, Abe M, Rujiravanit R. Structural and physicochemical characterization of crude biosurfactant produced by Pseudomonas aeruginosa SP4 isolated from petroleum-contaminated soil. Bioresour. Technol. 2008;99:1589-1595.

10. Guo YP, Hu YY, Gu RR, Lin H. Characterization and micellization of rhamnolipidic fractions and crude extracts produced by Pseudomonas aeruginosa mutant MIG-N146. J. Colloid Interface Sci. 2009;331:356-363.

11. Hanumantha Rao K, Vilinska A, Chernyshova IV. Minerals bioprocessing: R \& D needs in mineral biobeneficiation. $H y$ drometall. 2010;104:465-470.

12. Khoshdast H, Sam A. Flotation frothers: review of their classifications, properties and preparation. Open Miner. Process. J. 2011;4:25-44.

13. Fazaelipoor MH, Khoshdast H, Ranjbar M. Coal flotation using a biosurfactant from Pseudomonas aeruginosa as a froth- 
er. Korean J. Chem. Eng. 2010;27:1527-1531.

14. Engelbrecht JA, Woodburn ET. The effects of froth height, aeration rate, and gas precipitation on flotation. J. S. Afr. Inst. Min. Metall. 1975;76:125-132.

15. Banford AW, Aktas Z, Woodburn ET. Interpretation of the effect of froth structure on the performance of froth flotation using image analysis. Powder Technol. 1998;98:61-73.

16. Neethling SJ, Cilliers JJ. The entrainment of gangue into flotation froths. Int. J. Miner. Process. 2002;64:123-134.

17. Ekmekçi Z, Bradshaw DJ, Harris PJ, Buswell MA. Interactive effects of the type of milling media and $\mathrm{CuSO}_{4}$ addition on the flotation performance of sulphide minerals from Merensky ore part II: froth stability. Int. J. Miner. Process. 2006;78:164-174.

18. ChemSW. Chemsite pro demo software [Internet]. Fairfield: ChemSW Inc.; c2012. Availabe from: http://www.chemsw. com.

19. Hein M. Foundations of college chemistry: the alternative edition. New York: Brooks/Cole Publishing Company; 1980.

20. Luan F, Liu H, Gao Y, Li Q, Zhang X, Guo Y. Prediction of hydrophile-lipophile balance values of anionic surfactants using a quantitative structure-property relationship. J. Colloid Interface Sci. 2009;336:773-779.

21. Guo X, Rong Z, Ying X. Calculation of hydrophile-lipophile balance for polyethoxylated surfactants by group contribution method. J. Colloid and Interface Sci. 2006;298:441-450.

22. Bulatovic SM. Handbook of flotation reagents. Amsterdam: Elsevier; 2007.

23. Montgomery DC. Design and analysis of experiments. 5th ed. New York: John Wiley \& Sons; 2001.

24. Xia Y, Peng FF. Frothability characterization of residual organic solvents. Miner. Eng. 2007;20:241-251.

25. Cho YS, Laskowski JS. Effect of flotation frothers on bubble size and foam stability. Int. J. Miner. Process. 2002;64:69-80.
26. Melo F, Laskowski JS. Fundamental properties of flotation frothers and their effect on flotation. Miner. Eng. 2006;19:766-773.

27. Rezaei B. Flotation. Tehran: Tehran University Press; 1996.

28. Laskowski JS. Fundamental properties of flotation frothers. In: Proceedings of the 22nd International Mineral Processing Congress; 2003 Sep 29 - Oct 3; Cape Twon, South Africa. p. 788-797.

29. Laskowski JS. Testing flotation frothers. Physicochem. Prob. Miner. Process. 2004;38: 13-22.

30. Khoshdast H, Sam A, Manafi Z. Comparison of surface activity from rhamnolipid biosurfactants and industrial flotation frothers. In: The 1st National Copper Conference; 2011: Iran. p. 544-552.

31. Ishigami Y, Gama Y, Nagahora H, Yamaguchi M, Nakahara H, Kamata T. The $\mathrm{pH}$ sensitive conversion of molecular aggregates of rhamnolipid biosurfactant. Chem. Lett. 1987;16:763766 .

32. Boekhoven J. Self-assembling systems - research - orthogonal self-assembly. Delft: Delft University of Technology; 2009 [cited 2011 May 1]. Available from: http://www.tnw.tudelft. nl/live/css/styles_tamtam.css.

33. Benincasa M, Marqués A, Pinazo A, Manresa A. Rhamnolipid surfactants: alternative substrates, new strategies. In: Sen R, ed. Biosurfactants. New York: Springer Science; 2010. p. 170-184.

34. Champion JT, Gilkey JC, Lamparski H, Retterer J, Miller RM. Electron-microscopy of rhamnolipid (biosurfactant) morphology: effects of pH, cadmium, and octadecane. J. Colloid Interface Sci. 1995;170:569-574.

35. Özdemir G, Malayglu U. Wetting characteristics of aqueous rhamnolipids solutions. Colloids Surf. B Biointerfaces 2004;39:1-7. 